\title{
Challenges in the research of relative clause constructions in signed languages to date
}

\author{
Okan Kubus (Magdeburg-Stendal University of Applied Sciences) \\ okan.kubus@h2.de
}

\begin{abstract}
The main focus of the paper is to discuss how the complex occurrences of relative clause constructions in different signed languages can highlight dis-/ advantages of some methods of data collection and how we can best design studies to fully depict the realities of signed languages' discourse. I provide an overview of current insights into relative clause constructions in signed languages. I aim to reflect on the challenges works have faced to date and discuss how these might be overcome by pulling in approaches and methods not used (to their full potential) on this research topic so far. Eliciting data is a logical strategy to hopefully gain more insight into how relative clauses work in signed languages - however, we risk eliciting only very specific, limited occurrences and not getting the full picture which can only be found in more complex texts. Therefore, this overview shows how corpus studies on relative clause constructions could be a fruitful addition to the field in the future. To date, there are very few studies that have taken this approach that admittedly poses new challenges of understanding these constructions when they take wildly different forms in naturalistic data and employ markers that are both not obligatory and not limited to this specific construction.
\end{abstract}

Keywords: relative clause constructions, methodology, sign languages, data elicitation, corpora

\section{Motivation and outline of the paper}

I dove into this topic through doing research for my dissertation on relative clause constructions (RCCs) in Turkish Sign Language (TID; Kubus 2016). I started collecting the data by elicitation, asking participants to sign texts. This however yielded very few RCCs. To understand the nature of relative clauses (RCs) better, there was a need to add to my data pool. I was able to observe high numbers of RCCs in many online videos published by Turkish signers. These tokens exhibited very high variance in the realization of relative clauses in terms of lexical items, non-manual markers, and syntactic structures. With earlier studies about RCs in sign languages not mentioning this variance, we can ask: Why is it difficult to obtain data with RCCs? Why does this variation exist in this feature specifically, yet it is not mentioned in many works?

Obviously this feature comes with a range of challenges that must be dealt with, e.g. defining RCs in the first place (see e.g. Branchini 2014), textual and/or pragmatic factors (Kubus and Nuhbalaoğlu 2018), diachronic change in the complexity of RCs (Dachkovsky 2018), syntactic factors/typological perspective (Hauser et al. 2021), the implication of working memory on syntactic structures (Cecchetto, Giustolisi, and Mantovan 2016) and metalinguistic awareness ( Cormier et al. 2012). This paper focuses on methodology in studies 
on signed languages specifically. The main questions are: What are the challenges of the methodologies used to date? If we want to strive for more naturalistic data on RCs, how can we reach this goal when it comes to signed language research? When we then find wide variation in RCs as I have, and as others have in similar studies, how can we better understand this? And how can we design better stimuli regarding RCs for neuro- or psycholinguistic experiments?

I will start with an introduction showing how researchers have perceived and reported on the complexity of collection of RCs in signed language data to date. To put a focus on descriptive, experimental and or theoretical approaches to RCs in sign languages to date, I provide an overview of these studies in particular and their methodology. Three main methodologies are discussed in detail: (un-)guided elicitation methods, ${ }^{1}$ corpus studies and grammaticality judgment tests. Since there is no systematic corpus study on RCs in signed languages yet, I will provide some preliminary insight I gathered by using data from the DGS Corpus Project (Konrad et al. 2020). Lastly, I will summarize what we can learn by looking at the pros and cons of methodology used to look at this feature in signed languages.

\section{Overview of existing research on RCs in sign languages}

The first studies on RCs in signed languages were conducted on American, German and Italian Sign Language. Table 1 lists the most well-known studies on RCs in signed languages.

As seen there, Liddell $(1978,1980)$ first discussed the main properties of RCs in American Sign Language (ASL). RCs in ASL have been discussed extensively at the syntactic level (Coulter 1983; Fontana 1990). There is not much input on methodology however, because these first studies took a theoretical approach and were probably not based on systematically gathered and analyzed data.

After ASL, studies on RCs were next undertaken for Italian Sign Language (LIS) and German Sign Language (DGS) and in terms of methodology, some studies still stayed rather unspecific. Pfau and Steinbach (2005) outline the RCs in several studies including ASL (the studies listed above), LIS (see also the study of Cecchetto, Geraci, and Zucchi 2006) and Libras $^{2}$ (example is retrieved from Nunes and Quadros 2008).

Insight on RCs in a psycholinguistic context can be gained from Boudreault and Mayberry (2006). The authors conducted a grammaticality judgment test including simple sentences and sentences including negation, agreement verbs, wh-questions, relative clause constructions, and classifiers. They recruited 30 participants who were grouped into native, early and delayed first-language learners. The authors defined early learners' age of acquisition to be between 5 and 7 years and delayed first-language learners were defined as having acquired ASL from an age of 8 and 13 years. The authors do not mention any study on relative clauses in ASL, however, several grammatical and/or ungrammatical sentences including relative clauses were shown to the participants as part of the test. The examples used in the study and their impacts on the results are discussed in Section 3.2.

The signed language that has been featured in works on RCs most often is probably LIS. Some, but not all of these provide enough information on their methodology for us to learn something about how RCs showed up in their data. Cecchetto, Geraci, and Zucchi (2006) for

1. Some comprehension tasks (e.g., Hauser et al. 2021) regarding RCs use similar processes and therefore these tasks are discussed in the category named elicitation methods.

2. The authors use the abbreviation LSB, however, the current use of language for Brazilian Sign Language is Libras. Nunes and Quadros (2008) is not listed in Table 1 because the main focus of their study is not RCs and/or RCCs. 
Table 1: Research on RCs in sign languages and their methods (chronologically ordered)

\begin{tabular}{|c|c|c|}
\hline Study & Language & Methodology \\
\hline Liddell $(1978,1980)$ & ASL & Theoretical analysis \\
\hline Coulter (1983) & ASL & Theoretical analysis \\
\hline Fontana (1990) & ASL & Theoretical analysis \\
\hline Pfau and Steinbach (2005) & $\begin{array}{l}\text { ASL, } \\
\text { Libras, } \\
\text { LIS and } \\
\text { DGS }\end{array}$ & $\begin{array}{l}\text { Theoretical analysis and studies collected by } \\
\text { different authors }\end{array}$ \\
\hline $\begin{array}{l}\text { Boudreault and Mayberry } \\
\text { (2006) }\end{array}$ & ASL & $\begin{array}{l}\text { Grammaticality judgment test ( } n=30 \text {, three } \\
\text { different ages of ASL acquisition) }\end{array}$ \\
\hline $\begin{array}{l}\text { Cecchetto, Geraci, and Zuc- } \\
\text { chi (2006) }\end{array}$ & LIS & $\begin{array}{l}\text { Informants }(n=3 \text {, translating written sen- } \\
\text { tences })\end{array}$ \\
\hline Branchini and Donati (2009) & LIS & Informants $(\mathrm{n}=5)$ \\
\hline Tang, Lau, and Lee (2010) & HKSL & Informants $(n=3)$ \\
\hline Mosella Sanz (2011) & LSC & Informants $(\mathrm{n}=2)$ \\
\hline Rutkowski (2011) & PJM & Informants \\
\hline Brunelli (2011) & $\begin{array}{l}\text { LIS and } \\
\text { NGT }\end{array}$ & $\begin{array}{l}\text { NGT: informants }(n=3) \text {, translating written } \\
\text { sentences, then grammaticality judgment of } \\
\text { outputs. LIS: databases collected by different } \\
\text { authors and informants }\end{array}$ \\
\hline Donati and Cecchetto (2011) & LIS & Studies collected by different authors \\
\hline Cormier et al. (2012) & BSL & $\begin{array}{l}\text { Grammaticality judgment test ( } n=30 \text {, three } \\
\text { different ages of ASL acquisition) }\end{array}$ \\
\hline Branchini (2014) & LIS & $\begin{array}{l}\text { Data elicitation (naturalistic data for double } \\
\text { checking, } n=8 \text { ) }\end{array}$ \\
\hline $\begin{array}{l}\text { Cecchetto, Giustolisi, and } \\
\text { Mantovan (2016) }\end{array}$ & LIS & Studies collected by different authors \\
\hline $\begin{array}{l}\text { Kocab, Senghas, and } \\
\text { Snedeker (2016) }\end{array}$ & NSL & $\begin{array}{l}\text { Picture-based data elicitation ( } \mathrm{n}=27,3 \text { co- } \\
\text { horts) }\end{array}$ \\
\hline $\begin{array}{l}\text { Kubus (2016) and Kubus and } \\
\text { Nuhbalaoğlu (2018) }\end{array}$ & TİD & $\begin{array}{l}\text { Storytelling }(n=3) \text { and videos shared publicly } \\
(n=11)\end{array}$ \\
\hline Wilbur (2017) & ASL & Studies collected by different authors \\
\hline Dachkovsky $(2018,2020)$ & ISL & Picture-based elicitation (three cohorts, $n=29$ ) \\
\hline Hauser and Geraci (2018) & LSF & $\begin{array}{l}\text { Picture-based elicitation (+acceptability judg- } \\
\text { ment) }(n=2)\end{array}$ \\
\hline Hauser (2019) & LSF & $\begin{array}{l}\text { Picture-based elicitation (+acceptability judg- } \\
\text { ment), eye tracking }(n=33)\end{array}$ \\
\hline $\begin{array}{l}\text { Khristoforova and Kimmel- } \\
\text { man (2020) }\end{array}$ & RSL & $\begin{array}{l}\text { Picture-based elicitation, (+acceptability } \\
\text { judgment) }(n=9)\end{array}$ \\
\hline Hauser et al. (2021) & $\begin{array}{l}\text { LSC, } \\
\text { LSF, LIS }\end{array}$ & $\begin{array}{l}\text { Picture-based data elicitation (LSF, } \mathrm{n}=49 \text {; LIS, } \\
\mathrm{n}=44 \text {; LSC, } \mathrm{n}=42 \text {, three different groups ac- } \\
\text { cording to age of acquisition) }\end{array}$ \\
\hline
\end{tabular}


example asked three native signers to sign written inputs that contained RCs. The signed texts were then shown to the deaf community who judged them to be acceptable (p. 946). The authors were aware of the syntactical differences between written Italian and LIS and they hoped to minimize priming that would change the outcome by explicitly instructing the participants not to be influenced by the written examples. This illustrates one challenge in gathering data including RCs - if we elicit RCs from written language, it will be difficult to gather data that can be trusted as being representative of signed discourse. Branchini and Donati (2009) used a similar strategy and asked five deaf informants to produce sentences including RCs, and reported gathering homogenous data on RCs, despite some lexical differences reducible to dialectal variation and their initial disparity in meta-linguistic awareness (p. 2). They do not provide further information on how the data was obtained and their emphasis on very homogenous structures considering newer findings allows the assumption that the data was very much like the written input presented and hence, homogenous. The other studies on RCs in LIS like Donati and Cecchetto (2011) and Brunelli (2011), and Cecchetto, Geraci, and Zucchi (2006) are extensively theoretical. Brunelli (2011, 38-39) also looks at RCs in the Sign Language of the Netherlands (NGT) and devotes several pages to the methodology. Brunelli relies on databases obtained from several informants and different studies and emphasizes that no pictures or films were used as stimuli, rather a native signer translated RCCs from written language into their signed language (LIS or NGT). The videos were then shown to other informants to discuss the syntactical structures produced.

Some conference talks have mentioned RCs that may not exist in written academic papers. They look at other sign languages such as Hong Kong Sign Language (HKSL; Tang, Lau, and Lee 2010), Polish Sign Language (PJM; Rutkowski 2011) and Catalan Sign Language (LSC; Mosella Sanz $2011^{3}$ ). In these studies, relatively small groups of informants were used and instructed explicitly to present RCs.

In 2012, Cormier et al. (2012) conducted the grammaticality judgment test in British Sign Language (BSL) in analogy with the study Boudreault and Mayberry (2006) in ASL. Methodology and number of participants are alike the formerly mentioned examples. Branchini (2014) discusses methodological issues in Chapter 5 of her book. She makes extensive use of elicited data in her studies, but the corpus made up of more naturalistic data is used to double-check results and minimize the influence of spoken and/or written Italian. However, Branchini (2014) is aware of the methodological difficulties in finding any relative-like structures and thinks RCs are not used in everyday discussions (p. 179). However, she does not provide information like distribution of frequency, so the discussion stays rather general and it is hard for us to gather what structures were found and in what ways methodology may have influenced the results.

In my dissertation (Kubus 2016) and further studies like Kubus and Nuhbalaoğlu (2018), as mentioned above, publicly shared videos are used to investigate RCCs in TİD. This kind of methodology is also mentioned by Hou, Lepic, and Wilkinson (2020) who also find that using videos posted on the internet may open up a better way to get naturalistic data.

The studies published within the last five years on Nicaraguan Sign Language (NSL; Kocab, Senghas, and Snedeker 2016), Israeli Sign Language (ISL; Dachkovsky 2018, 2020), French Sign Language (LSF; Hauser and Geraci 2018) and Russian Sign Language (RSL; Khristoforova and Kimmelman 2020) are very strong in their methods of data elicitation. Most of the time the authors used picture stimuli and participants were then asked specific ques-

3. Marta Mosella Sanz (2012) has also written a dissertation on RCs in LSC; however, the language of dissertation is not English, and therefore, the author of this paper could not access it. The readers might look at Barberà (2020) to see RC examples from LSC which were collected in the context of the SIGN-HUB project. 
tions about the pictures' content to lead them to produce particular structures. This resembles the method that Branchini (2014) used, however, she avoided using any pictures. The researchers looked at similarities and differences among the strategies the signers used. Of course, if we look for more naturalistic data or a wider view on relative clauses, these are not really the studies that will have the same goals.

It is important to mention that Dachkovsky's $(2018 ; 2020)$ research goal is to observe the grammatical change in RCs in ISL and therefore, she compares three groups of ISL signers: those younger than 35 years, those of 35 to 55 years of age, and those older than the age of 55. The data elicitation strategy seems to work well with comparing these three groups.

Hauser (2019) in her dissertation combines data elicitation and eye tracking. She uses picture-based tasks to elicit RCs in LSF. This data is then watched by the informants, providing quantitative acceptability ratings, and (when relevant) inferential judgments. To understand the subject advantage of LSF RCs, she conducts visual world paradigm using eye tracking with LSF videos. In addition, Hauser et al. (2021) also use similar picture elicitation to compare RCs in three different sign languages, LIS, LSC and LSF, and use a comprehension task to see what sort of utterances were understood.

To summarize, we find that the first studies were theoretical works based on very few informants and some including elicitation through cross-linguistic comparison between written language and signed language. When we look at more recent studies, roughly three different methods appear to be used most: data elicitation, grammaticality judgment tests and corpus data. Of course, the first two strategies and a combination of the two have been extensively used and almost all of the studies mentioned the impracticability of conducting a corpus study. In the SignGram Blueprint - A Guide to Sign Language Grammar Writing, Branchini and Kelepir (2017) write on RCs: "Relative clauses create complex sentences not frequently occurring in spontaneous production. It is for this reason that it may be not easy to find them in a corpus containing only free conversational data .[...] it may be useful to use elicitation techniques that lead to the production of relative clauses in a semi-naturalistic setting“ (p. 456-457). Khristoforova and Kimmelman (2020) describe a similar issue in finding any RCs in a corpus, therefore, as a first step, data elicitation might be a useful step before conducting a corpus study. In the next subsections, each of these three methods will be looked at more closely.

\section{Comparing the methods of the research on relative clauses in sign languages}

\subsection{Elicitation methods}

The different ways of eliciting data including RCs can be grouped into three main strategies: asking the deaf informants to translate written text into signed language, asking questions after providing a context in signed language (as in e.g., Branchini 2014), and asking questions after showing pictures (as in e.g., 2020). It is obvious that the first strategy will lead to the least naturalistic data and invites the influence of code-switching between the two languages (see also the discussion in Branchini 2014), therefore this strategy will not be elaborated further.

In picture-based data elicitation, typically two or three similar people performing different actions are shown and informants are asked questions starting with "which" to obtain potential relative clauses. For example, Khristoforova and Kimmelman (2020) showed two similar boys, one reading a book sitting on the floor and one holding a pot standing up. The 
informants were then asked questions like "Which of the boys is reading a book?" or "Which of the boys do you like more?" With methods like this, it is of course important to instruct the informants not to answer too shortly by using only adjectives like "the right one" or pointing at the picture.

This strategy is ideal to compare groups and/or languages, indeed. However, there are some drawbacks to this strategy. First of all, in this case including a verb such as LIKE in "Which boy do you like more?" might already scew the data and not lead to the most representative results. Secondly, this strategy will lead to adjacent pairs (i.e. a dialogical form) instead of being contextual or textual. This also results in less variation because the question is so narrow that the informants will not produce a lot of variety in their signing (e.g. more cleft sentences instead of RCs). The content of such stimuli and questions is also highly accessible, and the function of RCs in these cases can only be disambiguation between a few options. Other functions of relative clauses, like retrieving old information or adding on explanation as described in my dissertation (Kubus 2016), probably won't occur even though they are commonly seen in natural signing. Moreover, the responses might show a high frequency of constructed action which may interact with the RCs in ways that have not been described, or be used instead of RCs, like depicting the target person's action instead of producing and utterance that we would typically code as an RCC.

The biggest use we can make of these methods, I would argue, is to use them as a first step, followed up by corpus research. Khristoforova and Kimmelman (2020) also mention that the current amount of variation in RCs they found is due to the stimulus and might look different (i.e. more variation) if they had different data: "We suspect that the amount of variation we found in RSL is not indicative of its typological peculiarity, but is an artifact of the methodology: when relying on mostly unguided picture-based production, as we did, or even more so on corpus data, as Kubus and Nuhbalaoğlu (2018) did, one finds more variation than when relying on judgment data from a small number of signers/speakers." (p. 62)

Showing two similar animate agents in stimuli may also lead to extensive use of subject relativization which could be another drawback. In order to minimize this effect, some researchers added third animate agents to observe the characteristics of object relativization (e.g., Hauser et al. 2021). By showing pictures including three referents, signers are given a choice between character perspective and observer perspective. However, for the comprehension tasks, it is very useful to check the typological differences around subject preference, same as Hauser et al. (2021) did by showing the participants signed video input and testing comprehension.

\subsection{Grammaticality judgment tests}

Another strategy is to test grammaticality of RCs, as done in Boudreault and Mayberry (2006) for ASL and Cormier et al. (2012) for BSL. Hauser (2019) also combined data elicitation with acceptability judgments. In the latter case, the number of participants is not high compared to the first two studies, so only the first two will be described more closely in this section.

The authors who used grammaticality tests including RCs compared three different groups, enabling them to gather finer-grained information on how different categories of utterances interacted with the performance of these different groups of informants. Each item category usually involved both grammatical and ungrammatical examples. Cormier et al. (2012) generated ungrammatical examples including some with RCs by changing the onset of the nonmanual element, in this case brow raise, and replacing the verb of the matrix clause with the relative clause itself: 
(1) Relative clause sentence with a plain verb (grammatical), Cormier et al. $(2012,55)$ brow raise

WOMAN CANCEL MEETING YESTERDAY ARRIVE

'The woman who cancelled the meeting yesterday has arrived.'

(2) Relative clause sentence with a plain verb (ungrammatical), Cormier et al. $(2012,56)$ brow raise

*ARRIVE WOMAN CANCEL MEETING YESTERDAY

'Arrive did the woman cancel the meeting yesterday?'

This example is interesting because signed languages are known to exhibit high flexibility in word order and also allow for extraposed relative clauses, at least for TİD (Kubus 2016). Due to this fact, we always should look at un-/grammaticality and examples we assume to fall in one of these categories with a grain of salt. In these studies, participants answered much faster and more correctly on grammatical over ungrammatical examples.

The results from these ASL and BSL grammaticality judgment tests show that relative clauses are the most complex sentence type, characterized by grammatical items being very easy to judge correctly, but not ungrammatical ones (see also the discussion in Lillo-Martin, Smith, and Tsimpli 2020). Cormier et al. (2012) think that this might be due to different levels of input in English and education systems, arguing participants might be influenced by what they know about written language and whether or not they think that signed utterances should resemble them. But I wonder whether it could also be the case that one RCC may be more typical, but there are also lots of different variations - this vast variety might lead to lots of confusion on what is ungrammatical because RCs might just be very varied and that might make it difficult to judge something as ungrammatical. Therefore, I argue that designing grammaticality judgment tests, especially where items appear isolated, without the context that we know is immensely important in signed discourse and grammar, carries the risk of creating circular arguments by creating and applying dichotomous labels that are then tested. We could still miss how big a spectrum of relativization strategies signed languages employ.

\subsection{Corpus studies}

Every year, the data that is collected within signed language corpora increases, which gives us a whole new realm of opportunities that simply did not exist before. However, the studies on RCs to date have not made much use of corpus data. Usually, corpus data is collected by setting signers up in a studio for a few hours and having them produce signed text, prompted by different tasks (Fenlon et al. 2015). Such studies are probably closest to fully naturalistic data. However, as mentioned earlier, the main drawback of corpus studies is that the RCs need to be detected in the first place, which is challenging in the case of a structure that is extensively marked only by nonmanual elements like brow raise and/or squint (see discussion in Branchini 2014 and Kubus 2016).

The DGS Corpus Project (Konrad et al. 2020) has collected a large amount of signed data, with part of them made available online to the general public and of course anyone who wants to do research on the data. In this section, I would like to outline possible processes to follow in corpus studies on relative clauses (Kubus, in progress), similar to what Klomp (2019) has done for finding conditional clauses. There are two possible ways to set up queries, using the provided annotations: looking for the manual markers that we expect to see and looking through the translated equivalents in written language. 
Pfau and Steinbach (2005) described nonhuman relative pronouns (INDEX) and human relative pronouns (SELBST- 'self') as manual relativization markers, so these can be used as potential queries for relative clauses in DGS. However, there are some issues: (i) the possibility of the high frequency (in the data from DGS Corpus Project, the nonhuman relative pronoun has over 25.000 and the human relative pronoun over 1.500 occurrences), (ii) these forms occur in many different functions and contexts and (iii), we will only find items that include these manual markers, when we know that these are not obligatory, again risking circular discourse. It seems that the nonhuman relative pronoun will be challenging as a clue to RCCs, but even SELBST is used in many different ways, albeit one is of course RCCs. In order to filter the results, as Klomp (2019) did for conditional clauses, I have looked at the German translations to find RCCs, which might point to RCCs in the DGS text. For this, I added potential German relative pronouns to the query, which selected 159 occurrences of SELBST out of $1.358(11,7 \%)$. The German relative pronouns that were added to the query can themselves also occur in many different functions, so I checked each occurrence individually. Table 2 shows the different German forms, tokens of these occurrences in the German translation, and the potential relative clauses in DGS to then compare how well the information that I got from the German translation fit what I then found in the DGS text.

Table 2: 'self' in DGS + relative pronouns in German

\begin{tabular}{|c|c|c|}
\hline $\begin{array}{l}\text { German relative pro- } \\
\text { nouns in translations }\end{array}$ & $\begin{array}{ll}\text { Number of to- } \\
\text { kens } & \text { before } \\
\text { checking } & \end{array}$ & $\begin{array}{l}\text { Number of tokens after checking and } \\
\text { leaving potential RCs in the data (leav- } \\
\text { ing } 25,15 \% \text {, } 40 \text { out of } 159 \text { ) }\end{array}$ \\
\hline ..., die ... & 58 & 18 \\
\hline$\ldots$, der ... & 33 & 16 \\
\hline ..., das ... & 55 & 5 \\
\hline ..., dem ... & 1 & 1 \\
\hline ..., denen ... & 0 & 0 \\
\hline ..., den ... & 6 & 0 \\
\hline ..., dessen ... & 2 & 0 \\
\hline ..., deren ... & 0 & 0 \\
\hline ..., welche* ... & 4 & 0 \\
\hline
\end{tabular}

These findings show that quite a few subject relative clauses can be found this way, which is also expected because most of the time the subject will be the agent, and this role is more likely to receive a RC. But for the aforementioned reasons, we have to assume that this is only one portion of the RCCs that could be found within the data, so writing such queries and using only or mostly that data will again lead to a biased dataset.

\section{Conclusion and thoughts on future research}

So far, three different main methodologies for understanding the occurrences of RCCs have been used. Every method has its own advantages and drawbacks. We could benefit from different methods to see the distribution and frequency of relative-like constructions in different text types.

Both in works from a theoretical as well as a prescriptive perspective, using the data of native signers is still very much the status quo (see discussion in Snoddon and De Meulder 2020). What I call prescriptive works here, may not be framed that way by the authors themselves - to my knowledge, not work on RCs in signed languages has called itself prescriptive. 
However, the status quo grants the question of whether choosing to put such emphasis on the group of native signers does not give any concurrent analysis and discussion prescriptive bias. This is a fact that will need further discussion and more conscious consideration since excluding all other signers does not serve all research questions - e.g., questions regarding documentation of how a signed language is being used and constructed currently. Also, when we know that variation among the community and within the language is that high and will continue to be so, we have to ask ourselves what we can really gain from only looking only at a more homogenous subgroup and gaining more homogenous data than what the reality presents (see also Occhino et al. 2021). One other important argument for seeking out variation in the data is that this way, we can also trace language use, for example grammaticalization in the case of relative clauses as Dachkovsky (2020) has pointed out.

Another issue is working memory (see discussion in Cecchetto, Giustolisi, and Mantovan 2016), as the use of subordination in signed languages may be highly dependent on the way the producer's working memory functions and how the signed text is perceived by interlocutors. Relative clauses draw heavily on their textual surroundings and thus cannot be analyzed in a meaningful way without these pragmatic and discourse considerations. Additionally, as Cormier et al. (2012) point out, performance in tasks on these phenomena will always be influenced by different educational backgrounds and familiarity with the surrounding written/spoken language.

Internet-based signed language data seems to be a very helpful resource to document relative clause constructions from deaf signers across different text types and even for conducting synchronic and diachronic research (Hou, Lepic, and Wilkinson 2020). As Hou, Lepic, and Wilkinson (to appear) discuss, the tradition of linguistic research with ASL-signing consultants in "researcher-controlled" contexts has unfortunately led to a constrained understanding of the structure of ASL due to the very narrow segment of the ASL-signing population included in such studies.

\section{References}

Barberà, Gemma. 2020. “Syntax: 3.4. Relative Clauses.” In A Grammar of Catalan Sign Language (LSC), edited by Josep Quer and Gemma Barberà, 230-237. SIGN-HUB Sign Language Grammar Series.

Boudreault, Patrick, and Rachel I. Mayberry. 2006. "Grammatical processing in American Sign Language: Age of first-language acquisition effects in relation to syntactic structure.” Language and Cognitive Processes 21 (5): 608-635. https: / / doi . org / 10 . 1080 / 01690960500139363.

Branchini, Chiara. 2014. On relativization and clefting: an analysis of Italian Sign Language. Boston: De Gruyter Mouton.

Branchini, Chiara, and Caterina Donati. 2009. "Italian Sign Language relatives: a contribution to the typology of relativization strategies." In Correlatives: Theory and typology, edited by Anikó Lipták, 157-191. Amsterdam: Elsevier.

Branchini, Chiara, and Meltem Kelepir. 2017. “3.4 Relative clauses.” In SignGram Blueprint A Guide to Sign Language Grammar Writing, edited by Josep Quer, Carlo Cecchetto, Caterina Donati, Carlo Geraci, Meltem Kelepir, Roland Pfau, and Markus Steinbach, 442-459. Boston: De Gruyter Mouton. 10.1515/9781501511806. 
Brunelli, Michele. 2011. "Antisymmetry and sign languages: A Comparison between NGT and LIS." Doctoral dissertation, University of Amsterdam.

Cecchetto, Carlo, Carlo Geraci, and Sandro Zucchi. 2006. "Strategies of relativization in Italian Sign Language.” Natural Language \& Linguistic Theory 24 (4): 945. https: / doi.org/ $10.1007 / \mathrm{s} 11049-006-9001-\mathrm{x}$.

Cecchetto, Carlo, Beatrice Giustolisi, and Lara Mantovan. 2016. "Short-Term Memory and Sign Languages. Sign Span and its Linguistic Implications.” Linguística: Revista de Estudos Linguísticos da Univerdade do Porto 11:59-89.

Cormier, Kearsy, Adam Schembri, David Vinson, and Eleni Orfanidou. 2012. "First language acquisition differs from second language acquisition in prelingually deaf signers: Evidence from sensitivity to grammaticality judgement in British Sign Language." Cognition 124 (1): 50-65. https://doi.org/10.1016/j.cognition.2012.04.003.

Coulter, Geoffrey R. 1983. "A conjoined analysis of American Sign Language relative clauses." Discourse Processes 6, no. 3 (July): 305-318. https:// doi.org/10.1080/0163853830954456 9.

Dachkovsky, Svetlana. 2018. "Grammaticalization of intonation in Israeli Sign Language: From information structure to relative clause relations." Doctoral dissertation, Haifa University.

2020. "From a demonstrative to a relative clause marker: Grammaticalization of pointing signs in Israeli Sign Language.” Sign Language \& Linguistics 23, no. 1 (October 30, 2020): 142-170. https://doi.org/10.1075/sll.00047.dac.

Donati, Caterina, and Carlo Cecchetto. 2011. "Relabeling heads. A unified account for relativization structures.” Linguistic Inquiry 42 (4): 519-560.

Fenlon, Jordan, Adam Schembri, Trevor Johnston, and Kearsey Cormier. 2015. "Documentary and corpus approaches to sign language research." In The Blackwell Guide to Research Methods in Sign Language Studies, edited by Eleni Orfanidou, Bencie Woll, and Gary Morgan, 156-172. Oxford: Blackwell.

Fontana, Joseph M. 1990. "Is ASL like Diegueño or Diegueño like ASL? A study of internally headed relative clauses in ASL." In Sign language research. Theoretical issues, edited by Ceil Lucas, 238-255. Washington, D.C.: Gallaudet University Press.

Hauser, Charlotte. 2019. "Subordination in LSF: nominal and sentential embedding." Doctoral dissertation, Université de Paris.

Hauser, Charlotte, and Carlo Geraci. 2018. "Relative clauses in French Sign Language (LSF): some preliminary results." FEAST. Formal and Experimental Advances in Sign language Theory, no. 1, 17-26. https://doi.org/10.2436/20.8050.03.2.

Hauser, Charlotte, Giorgia Zorzi, Valentina Aristodemo, Beatrice Giustolisi, Doriane Gras, Rita Sala, Jordina Sánchez Amat, Carlo Cecchetto, and Caterina Donati. 2021. "Asymmetries in relative clause comprehension in three European sign languages." Glossa: $a$ journal of general linguistics 6, no. 1 (May 31, 2021). https://doi.org/10.5334/gjgl.1454.

Hou, Lynn, Ryan Lepic, and Erin Wilkinson. 2020. "Working with ASL Internet Data." Sign Language Studies 21 (1): 32-67. https://doi.org/10.1353/sls.2020.0028. 
Hou, Lynn, Ryan Lepic, and Erin Wilkinson. to appear. "Managing sign language video data collected from the internet." In Open Handbook of Linguistic Data Management, edited by Andrea Berez-Kroeker, Bradley McDonnell, Eve Koller, and Lauren B. Collister. MIT Press.

Khristoforova, Evgeniia, and Vadim Kimmelman. 2020. "Syntax of relativization in Russian Sign Language: Basic features.” Voprosy Jazykoznaniia 6:48-65.

Klomp, Ulrika. 2019. "Conditional Clauses in Sign Language of the Netherlands: A CorpusBased Study.” Sign Language Studies 19 (3): 309-347. https:/ / doi.org/10.1353/sls.2019. 0000 .

Kocab, Annemarie, Ann Senghas, and Jesse Snedeker. 2016. "Recursion in Nicaraguan Sign Language." In Proceedings of the 38th Annual Conference of the Cognitive Science Society, edited by Anna Papafragou, Daniel Grodner, Daniel Mirman, and John C. Trueswell, 1343-1348. Austin, TX: Cognitive Science Society.

Konrad, Reiner, Thomas Hanke, Gabriele Langer, Dolly Blanck, Julian Bleicken, Ilona Hofmann, Olga Jeziorski, et al. 2020. MY DGS - annotated. Public Corpus of German Sign Language, 3rd release. Accessed October 25, 2020. https:/ /www.sign-lang.uni-hamburg. $\mathrm{de} /$ meinedgs/landing/corpus-3.0.html.

Kubus, Okan. 2016. “Relative Clause Constructions in Turkish Sign Language.” Doctoral dissertation, Universität Hamburg.

in progress. "Relative Clause Constructions in German Sign Language: A CorpusBased Study.” Unpublished Manuscript.

Kubus, Okan, and Derya Nuhbalaoğlu. 2018. "The challenge of marking relative clauses in Turkish Sign Language.” Dilbilim Araştırmaları Dergisi (July 2, 2018): 139-160. https : //doi.org/10.18492/dad.373454.

Liddell, Scott K. 1978. “An introduction to relative clauses in ASL.” In Understanding language through sign language research, edited by Patricia Siple, 59-90. New York: Academic Press.

- 1980. American Sign Language syntax. The Hagues: Mouton.

Lillo-Martin, Diane, Neil Smith, and Ianthi Tsimpli. 2020. "Age of acquisition effects in language development." In Understanding Deafness, Language and Cognitive Development: Essays in honour of Bencie Woll, edited by Gary Morgan, 93-113. Amsterdam: John Benjamins.

Mosella Sanz, Marta. 2011. "The position of fronted and postposed relative clauses in Catalan Sign Language.” Formal and Experimental Approaches to Sign Theory (FEAST). Venice.

. 2012. "Les construccions relatives en llengua de signes catalana (LSC).” Doctoral dissertation, University of Barcelona.

Nunes, Jairo, and Ronice Müller de Quadros. 2008. "Phonetically realized traces in American Sign Language and Brazilian Sign Language.” In Signs of time. Selected papers from TISLR 2004, edited by Josep Quer, 177-190. Hamburg: Signum. 
Occhino, Corrine, Jami N. Fisher, Joseph C. Hill, Julie A. Hochgesang, Emily Shaw, and Meredith Tamminga. 2021. "New Trends in ASL Variation Documentation." Sign Language Studies 21 (3): 350-377.

Pfau, Roland, and Markus Steinbach. 2005. "Relative clauses in German Sign Language: extraposition and reconstruction." In Proceeding of the North East Linguistic Society 35, edited by Leah Bateman and Cherlon Ussery, 2:507-521. Amherst: GLSA.

Rutkowski, Pawel. 2011. "The Syntax of Relative Clauses in Polish Sign Language (PJM): Some Empirical, Theoretical and Methodological Considerations.” Workshop „Complex Sentences and Beyond in Sign and Spoken Languages”. Lichtenberg-Kolleg, Georg-AugustUniversität Göttingen.

Snoddon, Kristin, and Maartje De Meulder. 2020. "Introduction: Ideologies in Sign Language Vitality and Revitalization.” Language and Communication 74:154-163.

Tang, Gladys, Prudence Lau, and Jafi Lee. 2010. "Strategies for relativization in HKSL. Paper presented at the conference." Theoretical Issues in Sign Language Research (TISLR) 10. Theoretical Issues in Sign Language Research (TISLR) 10.

Wilbur, Ronnie. 2017. "Internally-headed relative clauses in sign languages.” Glossa: a journal of general linguistics 2 (1). https://doi.org/10.5334/gjgl.183. 